\title{
The responsibilities of Health Authorities for medical education - an open letter to Deans and clinical tutors in light of impending changes to the National Health Service
}

\author{
Michael O’Brien
}

\author{
Regional Director of Public Health, East Anglian Regional Health Authority, Union Lane, Chesterton, \\ Cambridge CB4 IRF, UK.
}

Later this year-both the composition and style of action of Health Authorities will change as a result of the Government's White Paper 'Working for Patients' and when the consequential Health Services and Community Care bill reaches the statute book. Health Authorities will be smaller and more business-like. Their reduction in size means that the support of a substantial number of people who have gained experience and insight over their time as members of the existing Health Authorities will be lost. Many of the new members, styled nonexecutive directors, will be drawn from industry and commerce and will lack previous experience of health services management. That means that they will require induction and education themselves. One of the areas about which they will need information at the earliest stage is medical education lest it suffer as a result of lack of knowledge and therefore inappropriate attitude on their part. That is where you, Oh Deans and tutors, come in!

To underscore my view that there is a serious piece of education to be undertaken, I will recount three true tales. First of all, I remind you of an industrial tribunal which, some years ago, required a Regional Health Authority to re-employ someone who had been made redundant. The individual concerned had previously been employed as an associate specialist in mental handicap and the redundancy came about through closure of the institution in which he had worked. The tribunal to which he appealed took the view that he couldn't possibly be redundant because, at the same time, the Authority was advertising a vacancy. The fact that the vacancy was in thoracic medicine cut no ice with the members of the tribunal because a doctor is a doctor is a doctor! The members of the tribunal are not unique in their failure to understand the profound differences in knowledge and skill

Correspondence: M. O'Brien, Q.H.P., M.B., Ch.B., F.R.C.P., F.F.P.H.M., D.P.H.

Accepted: 8 May 1990 between medical people in different specialties even though they are all part of the same medical profession.

My second tale relates to the meeting between District clinical tutors and myself in one of the English health regions some years ago. I was challenged as to why the Regional Health Authority spent so little on postgraduate and continuing medical education. When I invited them to tell me how much was spent in each of their Districts, they did not know. Even when I was able to demonstrate to them that I did know and that in total the amount spent by that Regional Health Authority and its constituent districts was in excess of a million pounds a year, they persisted with their argument that it was too little. My counter was to the effect that 'until you know exactly what is spent in your district, what it is spent on, and what you are getting for that money, in my opinion the expenditure is too much, not too little'. It was an argument not too dissimilar from that which gave rise to the review of the National Health Service that in turn spawned the changes that are about to befall us. The lack of meaningful information about what the NHS achieves and at what unit cost is only the same debate which I had with the clinical tutors writ large. I feel quite sure that leaders of industry and commerce who are going to be enticed into directorships in the NHS, will adopt an approach similar to mine.

My third story relates to the first year I spent in my present post. I inherited a situation in which the budget for study leave for senior medical staff within the Region was grossly overspent. I had to resort to stopping all study leave for hospital consultants for six months! You can imagine the blistering correspondence that I received. It says at least two things. Firstly, I must be fairly robust and resilient because I am still here to write this letter and tell you the story. Secondly, and much more importantly, it underlines the fact that when finances are tight, education in general and study leave in particular represent a soft target ripe for 
cutting. Again, to emphasize the fact that this is not unique, I have seen my own younger daughter's graduate education stopped dead in its tracks because the firm for which she works, a subsiduary of a multi-national whose chairman is a household name, is currently in some difficulty. When revising the budget part way through the financial year the first of the cuts was in the field of education and training. It is perfectly possible therefore that new health service directors from similar backgrounds will bring similar attitudes with them.

All of which boils down to the fact that there is a job to be done by Deans and tutors to prepare the ground for the new authorities to ensure that they develop the right attitude to medical education and it needs to be done urgently. It means drawing together the threads of a number of activities including the pronouncements of the steering group on undergraduate medical and dental education (originally eponymously entitled the Partridge Committee and latterly the France Committee), the advice of the Standing Committee on Postgraduate Medical Education (SCOPME), the National Association of Clinical Tutors (NACT), the Committee of Regional Advisers in General Practice in England (CRAGPIE) and the report of the Chief Medical Officer's expert group (see Editorial, this issue, pages 799-800) on continuing medical education (and any other acronymic group which might be germane). What seems to me to be called for is a comprehensive description of medical education at all levels, and its significance for the service, to be prepared and presented to new authorities as they are convened. I will even be so bold as to suggest the form it might take.

Each Health Authority, Regional, District and Family Health Services Authority requires a statement of strategic intent within which its responsibilities for the provision of medical education can be fulfilled. The essential elements of such a statement are as follows -

1. A statement of the types of medical education:

(a) undergraduate, explaining its relationship with the year of provisional registration, (b) basic professional education, (c) higher professional training - specialist, (d) higher professional training - general practice vocational training and (e) continuing education.

With each of these sections a little description is called for to explain the contribution from the NHS to support the activities, particularly the clinical component of undergraduate medical education. Do not forget the service contribution made by the holders of training posts. It is also important to stress the contribution to the service in the sense that teaching improves the performance of the teacher. The longer term human resource and succession planning implications need to be stressed. These are very much in-vogue jargon phrases but as such will have a wealth of meaning for many of our new directors. In succession planning terms it will be particularly important to illustrate the lag between starting any one of the periods of education (a)-(e) inclusive and their bearing fruit.

The rationale for continuing education has to be rooted in the increase in medical and scientific knowledge applied to clinical practice, the rate of that increase, and also in a rising tide of interest in the issue of competence to practice. It is a crucial element in the professional development of individual doctors. A logical corollary is that improvements in education must be seen as a safeguard for patients.

2. A statement of the professional population to be served by the Authority - overall numbers, age structure, grade mix, distribution between hospital medicine, public health medicine and general practice; not forgetting those in non training, non consultant grades - clinical assistants, associate specialists, clinical and senior clinical medical officers, and staff doctors.

3. A statement of the present level of uptake of graduate medical education by specialty and by grade. This needs to be accompanied by a statement of costs to include expenditure on course and conference fees, travel and subsistence and locum fees if paid. Mention value for money. Opportunity costs, for example, whole time equivalent absences and service curtailments, should be balanced against costs of not providing graduate medical education in terms of reducing standard of service, potential inhibition on recruitment and in the extreme, potential litigation. Do not forget the costs and opportunity costs in general practice where time out is treated differently from the hospital and community health services.

4. A statement of perceived challenges: (a) financial, (b) educational and training facilities, (c) service constraints, (d) medical education infrastructure, particularly relationships with medical schools and graduate medical education facilities in district hospitals, (e) the need for provider units, including NHS Trusts ultimately, to identify clearly their plans for medical education, (f) the need for purchasers to require evidence that medical education obligations are being fulfilled and $(\mathrm{g})$ the need to accommodate the educational needs likely to be uncovered by the universal take up of medical audit activities.

5. A statement of the objectives of graduate medical education with targets/recommended standards by grade to ensure consistency of staff development through basic, higher specialist general practice vocational training (GVPT) and continuing education. It should be made 
clear that these targets are intended to balance skills training on the job with development of knowledge through educational processes off the job. There should also be targets for training of in-service trainers.

6. The price of the package. This could be set as a fixed percentage of total salary costs for medical and dental staff employed by the health authorities.

7. A statement of intent to evaluate medical education. This can be a simple count of by whom, when, where and at what cost graduate medical education is undertaken. It can also involve a disciplined attempt to measure the planned introduction of new knowledge and skills into the service, through the medical audit process.

I recognize that this is easily said and not necessarily easily done. Nevertheless, I believe that unless some attempt is made to undertake this evaluation it will be difficult to persuade our new directors that we are serious when we say that we intend to be prudent in the use of resources.
8. Description of a structure within which graduate medical education will be provided. This should identify a named responsible person accountable for the implementation of the strategy, the achievement of stated targets and for the management of the identified budget.

Who has the time to do all that? you will say and I understand immediately - it represents a very large task. But since before 'Working for Patients' I have heard many people say that more needs to be done for medical education. Since the publication of the White Paper there has been a veritable epidemic of anxiety about the fate of medical education. All that worry needs to be channelled into productive effort. If we really mean what we say - that medical education is vitally important, then it behoves us to make an approach of this nature co-ordinated across all regions. Unless we do so areas of medical education might continue to be looked at as a soft target. Together with Deans and others I intend to do this in my own Region. I do hope that you will feel able to make a similar approach in your own.

נים

